OPEN ACCESS

Edited by:

Roger Deal,

Emory University, USA

Reviewed by:

Maha Afifi,

California Table Grape Commission,

USA

Franz-Josef Schmitt,

Technical University of Berlin,

Germany

Agnese Magnani,

Università of Siena, Italy

*Correspondence:

Ankush Prasad

prasad-ank@tohtech.ac.jp

${ }^{\dagger}$ Co-corresponding author.

Specialty section:

This article was submitted to Technical Advances in Plant Science,

a section of the journal

Frontiers in Plant Science

Received: 27 May 2015

Accepted: 29 September 2015

Published: 15 October 2015

Citation:

Prasad A, Kumar A, Suzuki M, Kikuchi H, Sugai T, Kobayashi M, Pospíšl P, Tada M and Kasai S (2015)

Detection of hydrogen peroxide in

Photosystem II (PSII) using catalytic amperometric biosensor.

Front. Plant Sci. 6:862.

doi: 10.3389/fpls.2015.00862

\section{Detection of hydrogen peroxide in Photosystem II (PSII) using catalytic amperometric biosensor}

\author{
Ankush Prasad ${ }^{1 *}$, Aditya Kumar ${ }^{2}$, Makoto Suzuki ${ }^{3}$, Hiroyuki Kikuchi ${ }^{3}$, Tomoya Sugai ${ }^{3}$, \\ Masaki Kobayashi ${ }^{1,4}$, Pavel Pospíšil ${ }^{2}$, Mika Tada ${ }^{1,5}$ and Shigenobu Kasai ${ }^{1,3+}$ \\ ${ }^{1}$ Biomedical Engineering Research Center, Tohoku Institute of Technology, Sendai, Japan, ${ }^{2}$ Department of Biophysics, \\ Faculty of Science, Centre of the Region Haná for Biotechnological and Agricultural Research, Palacký University, Olomouc, \\ Czech Republic, ${ }^{3}$ Graduate Department of Environmental Information Engineering, Tohoku Institute of Technology, Sendai, \\ Japan, ${ }^{4}$ Graduate Department of Electronics, Tohoku Institute of Technology, Sendai, Japan, ${ }^{5}$ Center for General Education, \\ Tohoku Institute of Technology, Sendai, Japan
}

Hydrogen peroxide $\left(\mathrm{H}_{2} \mathrm{O}_{2}\right)$ is known to be generated in Photosystem II (PSII) via enzymatic and non-enzymatic pathways. Detection of $\mathrm{H}_{2} \mathrm{O}_{2}$ by different spectroscopic techniques has been explored, however its sensitive detection has always been a challenge in photosynthetic research. During the recent past, fluorescence probes such as Amplex Red (AR) has been used but is known to either lack specificity or limitation with respect to the minimum detection limit of $\mathrm{H}_{2} \mathrm{O}_{2}$. We have employed an electrochemical biosensor for real time monitoring of $\mathrm{H}_{2} \mathrm{O}_{2}$ generation at the level of sub-cellular organelles. The electrochemical biosensor comprises of counter electrode and working electrodes. The counter electrode is a platinum plate, while the working electrode is a mediator based catalytic amperometric biosensor device developed by the coating of a carbon electrode with osmium-horseradish peroxidase which acts as $\mathrm{H}_{2} \mathrm{O}_{2}$ detection sensor. In the current study, generation and kinetic behavior of $\mathrm{H}_{2} \mathrm{O}_{2}$ in PSIl membranes have been studied under light illumination. Electrochemical detection of $\mathrm{H}_{2} \mathrm{O}_{2}$ using the catalytic amperometric biosensor device is claimed to serve as a promising technique for detection of $\mathrm{H}_{2} \mathrm{O}_{2}$ in photosynthetic cells and subcellular structures including PSII or thylakoid membranes. It can also provide a precise information on qualitative determination of $\mathrm{H}_{2} \mathrm{O}_{2}$ and thus can be widely used in photosynthetic research.

Keywords: photosystem II, superoxide anion radical, hydrogen peroxide, reactive oxygen species, amperometric biosensor, EPR-spin trapping

\section{INTRODUCTION}

Photosystem II (PSII) is a multi-subunit pigment-protein complex which is located in the thylakoid membrane of chloroplasts of cyanobacteria, algae and higher plants that comprises of more than 25 proteins and the concomitant cofactors (Ferreira et al., 2004; Loll et al., 2005; Guskov et al., 2009; Kawakami et al., 2011). In plants, photosynthesis has been considered as a source of reactive oxygen species (ROS) production which works in close association with regulated mechanism of antioxidant network under normal conditions. The ROS in plants are known 
to be involved in cell toxicity, defense and signaling, and have been recently overviewed (Krieger-Liszkay, 2005; Foyer and Shigeoka, 2011; Schmitt et al., 2014).

Chlorophyll pigments of the PSII antenna complex absorb light energy and use it for the oxidation of water molecules and reduction of plastoquinone. Light energy absorbed by chlorophyll pigments converted into the energy of separated charges and consequent water-plastoquinone oxidoreductase activity is involuntarily linked with the production of ROS (Pospíšil, 2009, 2012). In unison, released molecular oxygen serves as a forerunner of ROS, which at low concentration play an important role in cell regulation, whereas if formed in excess, is responsible for oxidation of biomolecules such as lipid, proteins, and nucleic acid (Halliwell and Gutteridge, 2007). In addition, direct oxidation of proteins and lipids by UV irradiation and toxic chemicals following subsequent chemical reactions are also known to be associated with formation of ROS (Halliwell and Gutteridge, 2007; Prasad and Pospišil, 2012).

Production of ROS arises when excitation energy transfer to the PSII reaction center is inadequate or there is inhibition of electron transport chain in PSII. The redox couples in PSII covers a broad range of redox potential, it ranges from a very high negative value of redox couple, $\mathrm{Pheo} / \mathrm{Pheo}^{-}(E \mathrm{~m}=-610 \mathrm{mV})$ to a very high positive value of redox couple $\mathrm{P} 680^{+} / \mathrm{P} 680$ ( $E \mathrm{~m}=$ $+1250 \mathrm{mV}$ ) (Rappaport and Diner, 2008; Pospíšil, 2012). PSII is capable of either oxidizing water molecule or reducing molecular oxygen on the electron donor and on the electron acceptor side of the membrane, respectively (Pospišil, 2012). There is leakage of electrons to molecular oxygen during the electron transport on the electron acceptor side of PSII (Pospísil, 2009).

Formation of $\mathrm{O}_{2}^{\bullet-}$ results from non-enzymatic and enzymatic one-electron reductions of molecular oxygen. Pheophytin $\left(\right.$ Pheo $^{\bullet-}$ ) (Ananyev et al., 1994; Pospíšil et al., 2004), tightly bound plastosemiquinone $\left(\mathrm{Q}_{A}^{\bullet-}\right)$, (Cleland and Grace, 1999; Pospísil et al., 2004), loosely bound plastosemiquinone $\left(\mathrm{Q}_{B}^{\mathbf{}^{-}}\right)$, (Zhang et al., 2003; Yadav et al., 2014), and free plastosemiquinone $\left(\mathrm{PQ}^{\bullet-}\right)$ (Mubarakshina and Ivanov, 2010) maintains non-enzymatic reduction of molecular oxygen to $\mathrm{O}_{2}^{\bullet-}$. Heme iron of low-potential (LP) form of cyt $b_{559}$ reduces molecular oxygen to $\mathrm{O}_{2}^{\bullet-}$ in the enzymatic reaction pathway (Pospíšil et al., 2006; Pospišil, 2011).

One electron reduction of $\mathrm{O}_{2}^{\bullet-}$ either via non-enzymatic or enzymatic reaction pathway results in the formation of $\mathrm{H}_{2} \mathrm{O}_{2}$. In spontaneous dismutation, $\mathrm{O}_{2}^{\bullet-}$ provides an additional electron to another $\mathrm{O}_{2}^{--}$, and then with protonation brings about the formation of $\mathrm{H}_{2} \mathrm{O}_{2}$. In enzymatic dismutation, the ferrous heme iron of HP form of cyt $b_{559}$ drives the catalysis of one-electron reduction of $\mathrm{HO}_{2}^{*}$ to $\mathrm{H}_{2} \mathrm{O}_{2}$ (Tiwari and Pospísil, 2009; Pospišil, 2011). Spontaneous dismutation is preferred where there is availability of protons e.g., at the membrane edge while PSII metal centers are chosen to catalyze the dismutation reaction in the interior of the membrane (Pospísil, 2012). The one-electron reduction of $\mathrm{O}_{2}^{\bullet-}$ to $\mathrm{H}_{2} \mathrm{O}_{2}$ is catalyzed by superoxide dismutase (SOD) and is known to occur predominantly in the mitochondria, peroxisomes, and cytoplasm. At the physiological $\mathrm{pH}$, the dismutation reaction is preferably catalyzed by SOD.
Several spectroscopic techniques (fluorescence and chemiluminescence) and chromatographic techniques (high performance liquid chromatography coupled with peroxyoxalate chemiluminescence detection) have been used in the past for the determination of $\mathrm{H}_{2} \mathrm{O}_{2}$ in living cells (Mills et al., 2007; Chen et al., 2009; Ahammad, 2013). Light induced production of $\mathrm{H}_{2} \mathrm{O}_{2}$ have been measured in PSII membranes by oxidation of thiobenzamide with lactoperoxidase. Thiobenzamide sulfoxide was quantified by its absorbance at $370 \mathrm{~nm}$ (Schröder and Åkerlund, 1990; Arató et al., 2004; Pospíšil et al., 2004). Production of $\mathrm{H}_{2} \mathrm{O}_{2}$ by chloroplasts have been measured by the AmplexRed fluorescence assays (Mubarakshina and Ivanov, 2010; Yadav and Pospísil, 2012). Hydrogen peroxide $\left(\mathrm{H}_{2} \mathrm{O}_{2}\right)$ detecting probes, 3,3 diaminobenzidine (DAB), Amplex Red (AR), Amplex Ultra Red (AUR), and a europium-tetracycline complex (Eu3Tc) have been compared by infiltrating into tobacco leaves and tested for sensitivity to light, toxicity, subcellular localization, and capacity to detect $\mathrm{H}_{2} \mathrm{O}_{2}$ in vivo (Šnyrychová et al., 2009). The induction of $\mathrm{H}_{2} \mathrm{O}_{2}$ generation at the leaf level after 3-acetyl-4-hydroxyl-5-isopropylpyrroline-2dione (3-AIPTA) or bentazon treatment has been detected by performing histochemical analysis with 3, 3 DAB staining (Chen et al., 2012). Apart from several spectroscopic techniques (absorbance, fluorescence, chemiluminescence), cyclic voltammetry and histochemical technique, a reporter system based on HSP70A promoter-luciferase fusions have also been developed in past for the detection of $\mathrm{H}_{2} \mathrm{O}_{2}$ in vivo (Shao et al., 2007).

In the electrochemical method, mediator and non-mediator based electrode have been used in the past. Among the mediator based modified electrodes, HRP is the most commonly used material for the modification of the electrode in the last decade (Lin et al., 2000; Camacho et al., 2007; Radi et al., 2009; Ahammad, 2013). The sensitivity and selectivity of $\mathrm{H}_{2} \mathrm{O}_{2}$ biosensor depends on the material used and modifications involved (Lin et al., 2000; Nakabayashi and Yoshikawa, 2000; Yao et al., 2005; Wang and Zhang, 2006; Camacho et al., 2007; Radi et al., 2009; Inoue et al., 2010; Li et al., 2013). The mechanism of detection of $\mathrm{H}_{2} \mathrm{O}_{2}$ biosensor is described in Scheme 1. The enzyme HRP is converted to its oxidized form, which is than reduced at the surface of the carbon electrode by the transfer of the electron via the mediator. Different mediators have been used in the past including methylene blue (Lin et al., 2000; Kafi et al., 2009; Tiwari and Singh, 2011); quinones predominantly hydroquinones (Lei et al., 2004, 2005; Zhang et al., 2008; Yang et al., 2010); ferrocene (Wang et al., 2005; Senel et al., 2010), and ferrocene carboxylic acid (Tian et al., 2001; Tripathi et al., 2006; Liu et al., 2011; Luo et al., 2011). The detection limit in utmost cases were found to be in the concentration range of units of millimolar or micromolar $(\mu \mathrm{M})$ while a limited reports showed detection limit in tens of nanomolar (nM) concentration (Zhang et al., 2008; Loew et al., 2009; Lu et al., 2010). Recently, Os-HRP was compared with native HRP based coated glassy carbon electrode and it was found to possess high sensitivity for hydroperoxide. The electrodes were tested for $\mathrm{H}_{2} \mathrm{O}_{2}$ and hydroperoxide in the concentration range of $0.01-1 \mu \mathrm{M}$ (Loew et al., 2009). 


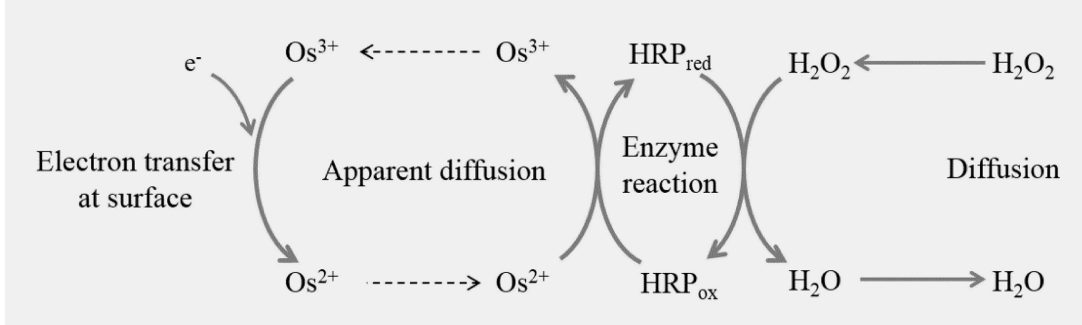

Electrode Osmium peroxidase polymer Sample

SCHEME 1 | Working principle of catalytic amperometric biosensor device: schematic illustration shows the working principle of Osmium-horseradish peroxidase (Os-HRP) modified carbon electrode depicting the oxidation-reduction cycle leading to generation of reduction current for $\mathrm{H}_{2} \mathrm{O}_{2}$.

Non-mediator based $\mathrm{H}_{2} \mathrm{O}_{2}$ biosensor has also been widely used in the past; however, it is known that the electron transfer between HRP and the electrode is difficult due to higher distance between the active site of HRP and the electrode. The voltammetric detection of $\mathrm{H}_{2} \mathrm{O}_{2}$ at carbon electrodes is challenging due to the slow electron transfer kinetics associated with the irreversible oxidation of peroxide. An anodic scan has been used as an electrochemical pretreatment and a rapid, sensitive and selective voltammetric method has been developed for the detection of physiological concentrations of $\mathrm{H}_{2} \mathrm{O}_{2}$ at uncoated carbon fiber microelectrodes (Sanford et al., 2011).

In this study, we provide an experimental evidence on the detection of $\mathrm{H}_{2} \mathrm{O}_{2}$ by using Osmium (Os) as a mediator which promotes shuttling of electrons between the electrode and the enzyme. Detection of $\mathrm{H}_{2} \mathrm{O}_{2}$ by using highly sensitive and selective Os-HRP modified electrode was tested in PSII membrane under light illumination. The current study introduces the use of catalytic amperometric biosensors in detection of low level of $\mathrm{H}_{2} \mathrm{O}_{2}$ production in PSII membrane.

\section{MATERIALS AND METHODS}

\section{Material and Chemical Reagents}

5-(ethoxycarbonyl)-5-methyl-1-pyrroline N-oxide (EMPO) spin trap was obtained from Alexis Biochemicals (Lausen, Switzerland). Capillary tube used for Electron paramagnetic resonance (EPR) measurements was purchased from Blaubrand intraMARK, Brand, Germany. All other chemicals of analytical grade were purchased either from Wako Pure Chemicals Industries, Ltd. (Osaka, Japan), Sigma-Aldrich chemie Gmbh (Munich, Germany), or Sigma-Aldrich Japan K.K (Tokyo, Japan).

\section{Preparation of PSII Membrane}

Photosystem II (PSII) membranes were prepared from fresh spinach leaves using the method reported previously by Berthold et al. (1981) with modifications described by Ford and Evans (1983). All steps during the isolation procedure were done at $4^{\circ} \mathrm{C}$ in green light using green LED strip (Photon Systems Instruments (PSI), Drásov, Czech Republic) or under dark condition using different buffers (A and B). The composition of buffer A ( $\mathrm{pH} 7.5$ ) being $400 \mathrm{mM}$ sucrose, $15 \mathrm{mM} \mathrm{NaCl}$, $5 \mathrm{mM} \mathrm{MgCl}_{2}, 5 \mathrm{mM} \mathrm{CaCl}_{2}, 40 \mathrm{mM}$ HEPES (pH 7.5), $5 \mathrm{mM}$ $\mathrm{Na}$-ascorbate, and $2 \mathrm{~g} / \mathrm{l}$ bovine serum albumin (BSA) while buffer B was composed of $400 \mathrm{mM}$ sucrose, $15 \mathrm{mM} \mathrm{NaCl}$ and $5 \mathrm{mM} \mathrm{MgCl}_{2}, 40 \mathrm{mM}$ MES (pH 6.5). Spinach leaves were washed twice with deionized water. $\mathrm{Na}$-ascorbate and BSA were added immediately before crushing the spinach leaves. Dark adapted leaves $(400 \mathrm{~g}$ ) were homogenized with $500 \mathrm{ml}$ of buffer A. This step was followed by filtering the homogenized mixture through 2 layers of nylon bolting cloth. Filtrate was transferred into ice-chilled centrifugation tubes and was centrifuged for $10 \mathrm{~min}$ at $9950 \times \mathrm{g}$ at $4^{\circ} \mathrm{C}$. The supernatant was thrown out and pellet was mixed properly with paint brush. The pellet was then resuspended in $600 \mathrm{ml}$ of buffer $\mathrm{B}$ and again centrifuged at $9950 \times \mathrm{g}$ for $10 \mathrm{~min}$ at $4^{\circ} \mathrm{C}$. After the centrifugation, supernatant was discarded and pellet was again resuspended in buffer B, at this step concentration of chlorophyll was measured. This step was followed by treating the suspension with $5 \%$ Triton X100 on ice bath with continuous stirring for $17 \mathrm{~min}$, and then centrifugation at $7000 \times \mathrm{g}$ for $7 \mathrm{~min}$. The pellet was discarded and supernatant was centrifuged again at 48,000 $\times$ g for $20 \mathrm{~min}$ at $4^{\circ} \mathrm{C}$. Pellet was washed for 3 times with buffer $\mathrm{B}$ and at the final step, and chlorophyll concentration was measured. PSII membrane were diluted to final chlorophyll concentration (3-6 $\mathrm{mg} \mathrm{Chl} \mathrm{ml}^{-1}$ ) and were stored at $-80^{\circ} \mathrm{C}$ until further use.

Chlorophyll concentration was determined in aqueous $80 \%$ $(\mathrm{v} / \mathrm{v})$ acetone by absorbance at 646 and $663 \mathrm{~nm}$ according to the method described by Lichtenthaler (1987).

\section{Light Illumination}

PSII membranes were exposed to continuous white light $\left(1,000 \mu \mathrm{mol}\right.$ photons $\left.\mathrm{m}^{-2} \mathrm{~s}^{-1}\right)$ for time period as required during the different experimental setups. The illumination was performed using halogen lamps with a light guide (KL1500 Electronic, Schott, Mainz, Germany and PL075, Hoya Candeo 
Optonics, Japan). The light intensity was measured by quantum radiometer LI-189 and LI-185B (LI-COR Inc., Lincoln, U.S.A.).

\section{Electron Paramagnetic Resonance (EPR) Spin-trapping Spectroscopy}

The detection of $\mathrm{O}_{2}^{\bullet-}$ was performed by EPR spin-trapping spectroscopy. Superoxide anion radical was detected by spin trapping using EMPO, 5-(ethoxycarbonyl)-5-methyl-1-pyrroline N-oxide. The experimental conditions are as follows: PSII

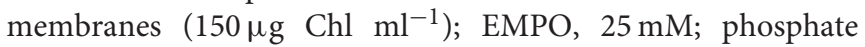
buffer, $40 \mathrm{mM}$ ( $\mathrm{pH}$ 6.5), DCMU, $20 \mu \mathrm{M}$ and desferal, $50 \mu \mathrm{M}$. Spectra were recorded using EPR spectrometer Mini Scope MS400 (Magnettech GmbH, Berlin, Germany) with EPR conditions as follows: microwave power, $10 \mathrm{~mW}$; modulation amplitude, $1 \mathrm{G}$; modulation frequency, $100 \mathrm{kHz}$; sweep width, $100 \mathrm{G}$; scan rate, $1.62 \mathrm{G} \mathrm{s}^{-1}$. Formation of light-induced EMPO-OOH adduct EPR spectra was measured in PSII membranes after illumination of PSII membranes in glass capillary tube with continuous white light $(1000 \mu \mathrm{mol}$ photons $\left.\mathrm{m}^{-2} \mathrm{~s}^{-1}\right)$.

\section{Fabrication of Osmium-HRP (Os-HRP) Modified Carbon Electrode}

The electrochemical biosensor used in the study was prepared using carbon-electrode (BAS Inc, ALS Co., Ltd., Japan). Prior to each measurement, the carbon electrode was cleaned using PK-3 Electrode Polishing Kit (BAS Inc., ALS Co., Ltd., Japan) with the aim to remove redox reaction products accumulated on the electrode surface. This step was followed by spreading/dropping of $0.5 \mu \mathrm{L}$ aliquot of Os-HRP polymer solution (Bioanalytical System, USA) on the carbon electrode $(\varphi, 1 \mathrm{~mm})$. The solution was allowed to form a circular thin film after overnight drying at $4^{\circ} \mathrm{C}$ under dark condition.

\section{Cyclic Voltammetry of Os-HRP Modified Carbon Electrode}

For the basic characterization of the Os-HRP modified carbon electrode, a portion of the electrode was soaked in $10 \mathrm{ml}$ of $40 \mathrm{mM}$ Na-phosphate buffer and cyclic voltammetry was performed. Cyclic voltammetry was conducted at a scan rate of $20 \mathrm{mV} / \mathrm{s}$ from 0.0 to $+0.5 \mathrm{~V}$ at room temperature.

\section{Hydrogen Peroxide Detection using Catalytic Amperometric Biosensor}

The electrochemical measurements were performed using a potentiostat (HA1010mM4S; Hokuto Denke Co. Ltd., Japan). For the assay to study $\mathrm{H}_{2} \mathrm{O}_{2}$ generated in PSII membrane, the PSII membranes at a concentration of $150 \mu \mathrm{g} \mathrm{Chl} \mathrm{ml}{ }^{-1}$ was introduced into a six well Repro plate (IFP, Research unit for the functional peptides, Yamagata, Japan). $\mathrm{Ag} / \mathrm{AgCl}$ electrode was used as a reference electrode and Os-HRP modified carbon electrode was used as working electrode. Platinum plate in the dimension of $5^{*} 5^{*} 0.1 \mathrm{~mm}$ was used as a counter electrode. Kinetics on the formation of light-induced $\mathrm{H}_{2} \mathrm{O}_{2}$ was measured in PSII membranes after illumination under continuous white light $\left(1000 \mu \mathrm{mol}\right.$ photons $\left.\mathrm{m}^{-2} \mathrm{~s}^{-1}\right)$ for a duration of $1 \mathrm{~h}$. The sampling time was kept at $500 \mathrm{~ms}$.

\section{RESULTS}

\section{Superoxide Anion Radical Production in PSII Membranes}

The light-induced formation of $\mathrm{O}_{2}^{\bullet-}$ in PSII membranes was measured using EPR spin-trapping spectroscopy. The spin-trapping was accomplished by the spin-trap compound 5-(ethoxycarbonyl)-5-methyl-1-pyrroline N-oxide (EMPO). The EMPO did not induce any EMPO-OOH adduct EPR signal in non-illuminated PSII membranes, whereas illumination with a

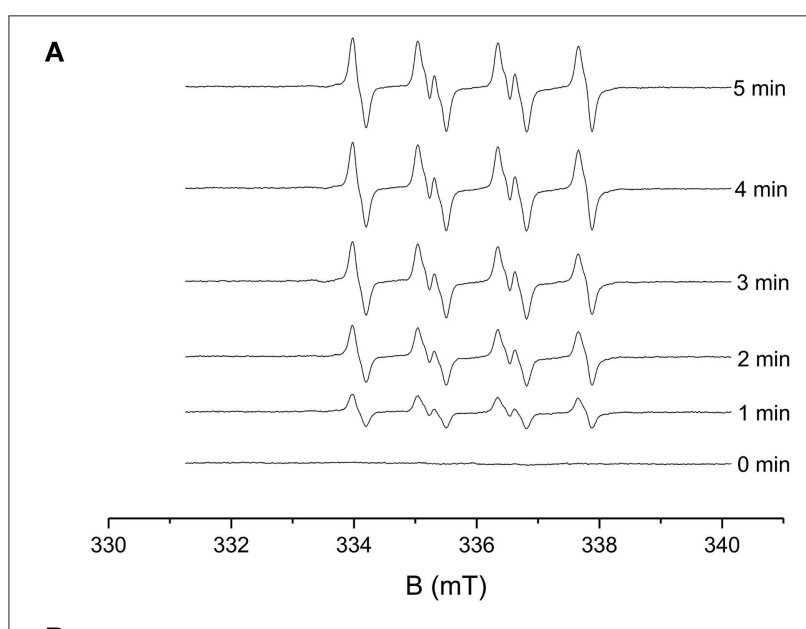

B

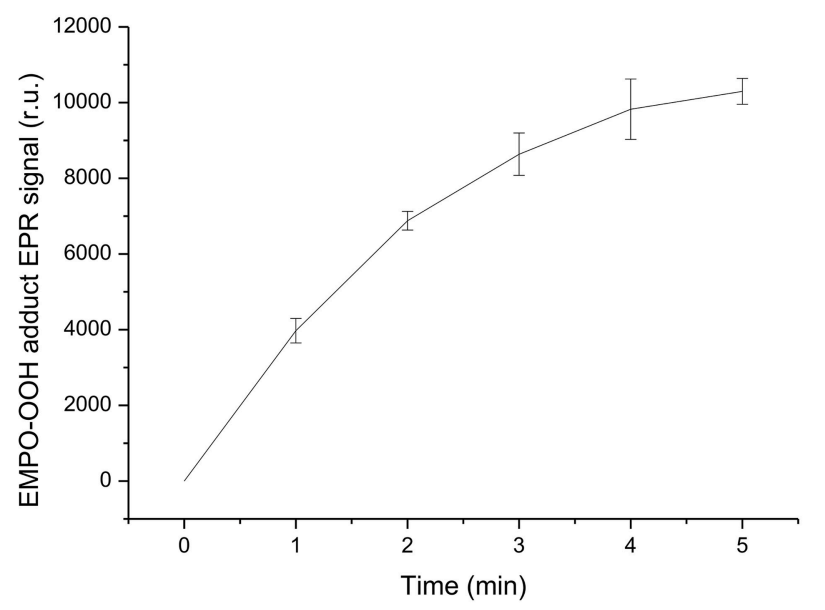

FIGURE 1 | Light-induced EMPO-OOH adduct EPR spectra measured in PSII membranes. EMPO-OOH adduct EPR spectra were measured under light illumination (1000 $\mu \mathrm{mol}$ photons $\mathrm{m}^{-2} \mathrm{~s}^{-1}$ ) of PSII membranes (150 $\mu \mathrm{g}$

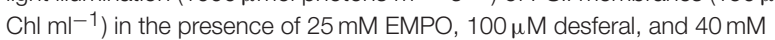
phosphate buffer ( $\mathrm{pH}$ 6.5). (A) Shows the spectra measured in the time range of 0-5 min of illumination and 1 (B) shows time profile of EMPO-OOH adduct EPR spectra. The intensity of EPR signal was evaluated by measuring the relative height of central peak of the first derivative of the EPR absorption spectrum. The data represent the mean value $( \pm \mathrm{SD})$ where $n=3$. 
continuous white light $\left(1,000 \mu \mathrm{mol}\right.$ photons $\left.\mathrm{m}^{-2} \mathrm{~s}^{-1}\right)$ resulted in the formation of the EMPO-OOH adduct EPR signal (Figure 1A). Time dependence of EMPO-OOH adduct EPR signal shows that formation of $\mathrm{O}_{2}^{\bullet-}$ is enhanced linearly for a duration upto $5 \mathrm{~min}$ of light illumination (Figure 1B). These results suggest that illumination of PSII membranes with a continuous white light $\left(1,000 \mu \mathrm{mol}\right.$ photons $\left.\mathrm{m}^{-2} \mathrm{~s}^{-1}\right)$ results in $\mathrm{O}_{2}^{\bullet-}$ production.

\section{Effect of Superoxide Dismutase and Catalase on $\mathrm{O}_{2}^{--}$Production in PSII Membranes}

To study the contribution of $\mathrm{O}_{2}^{\bullet-}$ leading to $\mathrm{H}_{2} \mathrm{O}_{2}$ formation in PSII membranes under light illumination, the effect of SOD and catalase (CAT) were studied on $\mathrm{O}_{2}^{\bullet-}$. Upon addition of exogenous SOD, which is known to catalyze the dismutation of $\mathrm{O}_{2}^{\bullet-}$ to $\mathrm{H}_{2} \mathrm{O}_{2}$ to PSII membranes prior to illumination, EMPO-OOH adduct EPR signal was found to diminish completely. The simultaneous addition of SOD and CAT was also found to suppress the EMPO-OOH EPR signal completely (Figure 2A). This observation indicates that $\mathrm{O}_{2}^{\bullet-}$ produced during light illumination is most likely involved in $\mathrm{H}_{2} \mathrm{O}_{2}$ formation in PSII membranes.

\section{Effect of DCMU on $\mathrm{O}_{2}^{\circ-}$ Production in PSII Membranes}

The effect of herbicides, DCMU [3-(3,4-dichlorophenyl)-1,1dimethylurea] (Sigma Aldrich, Germany) was tested for its effect on EMPO-OOH adduct EPR signal in PSII membranes. The effect of DCMU which is known to block the electron transfer from $\mathrm{Q}_{A}$ to $\mathrm{Q}_{B}$ was studied on light-induced formation of $\mathrm{O}_{2}^{\bullet-}$. Figure $2 \mathrm{~B}$ shows that the addition of DCMU suppressed EMPO-OOH adduct EPR signal approximately by $50 \%$ (Figure 2B). These observations indicate that loosely bound plastosemiquinone bound at or after the $\mathrm{Q}_{B}$ site can contribute to the overall production of $\mathrm{O}_{2}^{\bullet-}$ via the reduction of molecular oxygen.

\section{Characterization of Os-HRP Modified Carbon Electrode}

The characterization of the Os-HRP modified carbon electrode was performed using cyclic voltammetry (Figure 3). Cyclic voltammetry was conducted at a scan rate of $20 \mathrm{mV} / \mathrm{s}$ from 0.0 to $+0.5 \mathrm{~V}$ at room temperature. The oxidation and reduction current were obtained at $0.3 \mathrm{~V}$ vs. $\mathrm{Ag} / \mathrm{AgCl}$. Based on the data obtained, the surface concentration of Os-HRP on the carbon electrode was calculated to be $6.78 \times 10^{-9} \mathrm{~mol} / \mathrm{cm}^{2}$. The Calibration curve of Os-HRP modified carbon electrode was also measured using standard $\mathrm{H}_{2} \mathrm{O}_{2}$ solution (Supplementary Data).

\section{Hydrogen Peroxide Production in PSII Membranes}

The light-induced formation of $\mathrm{H}_{2} \mathrm{O}_{2}$ in PSII membranes was measured using catalytic amperometric biosensor. The study of kinetics of $\mathrm{H}_{2} \mathrm{O}_{2}$ production was accomplished using Os-HRP modified carbon electrode. The reduction current generated in the presence of $\mathrm{H}_{2} \mathrm{O}_{2}$ was monitored. Under dark condition, no change in the reduction current was observed whereas illumination with a continuous white light $(1,000 \mu \mathrm{mol}$ photons $\mathrm{m}^{-2} \mathrm{~s}^{-1}$ ) resulted in change in the reduction current. Figure 4A shows typical chronoamperometric responses, the reduction currents gradually increased after light illumination followed by a shoulder which continues for a duration of about $1 \mathrm{~h}$ which than rapidly drops at the switching off the light (dark period). The peak value of the reduction current was reached after about $15 \mathrm{~min}$ of light illumination with a maximum change in reduction currents of approximately $400 \mathrm{pA}$. The data presented shows continuous generation of $\mathrm{H}_{2} \mathrm{O}_{2}$ till the period of light illumination (Figure 4A). These results shows that illumination of PSII membranes with continuous white light results in $\mathrm{H}_{2} \mathrm{O}_{2}$ production.

\section{Effect of SOD and CAT on $\mathrm{H}_{2} \mathrm{O}_{2}$ Production in PSII Membranes}

To monitor the functionality of the sensor, the effect of SOD was measured under light-illumination. Reduction current for $\mathrm{H}_{2} \mathrm{O}_{2}$ was measured for first $5 \mathrm{~min}$ of light illumination where

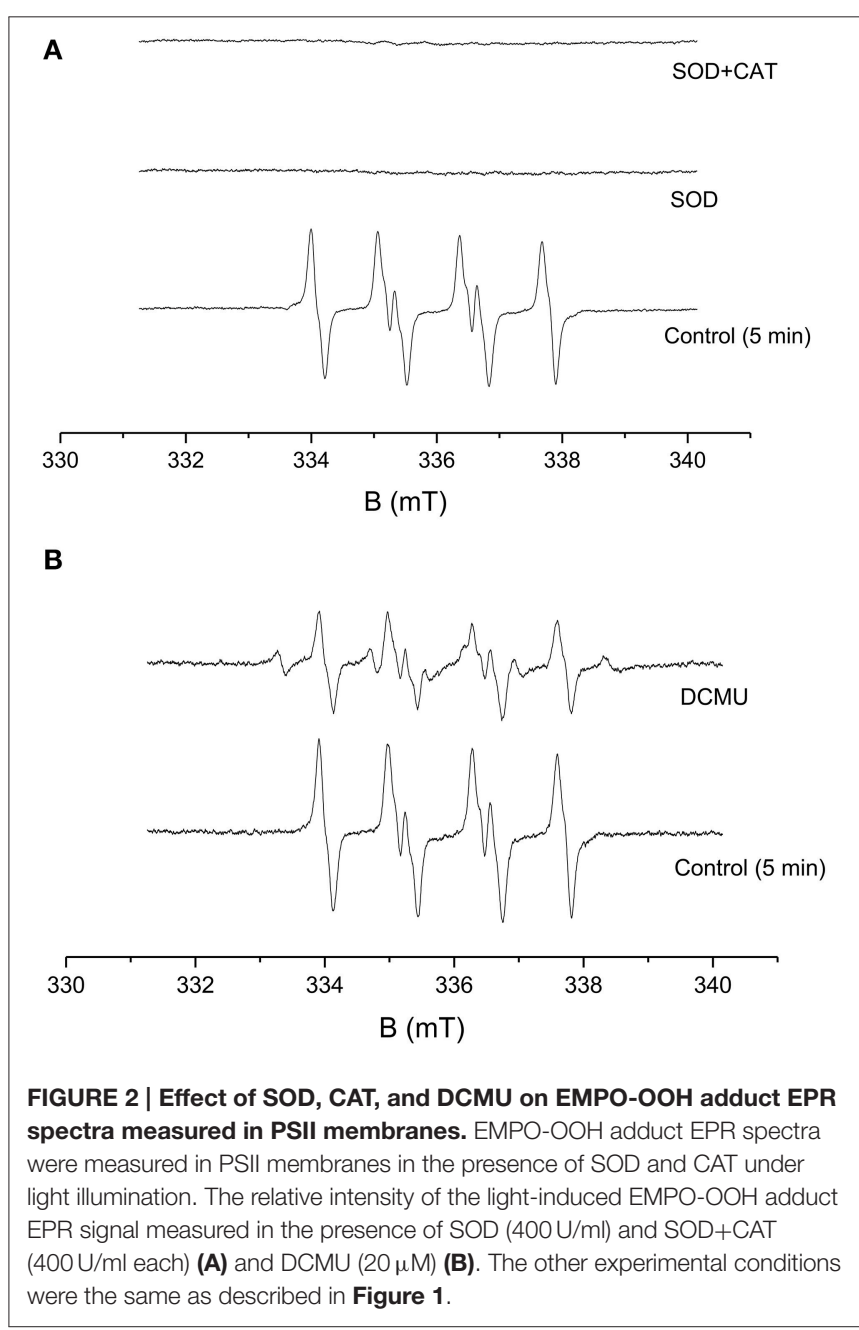




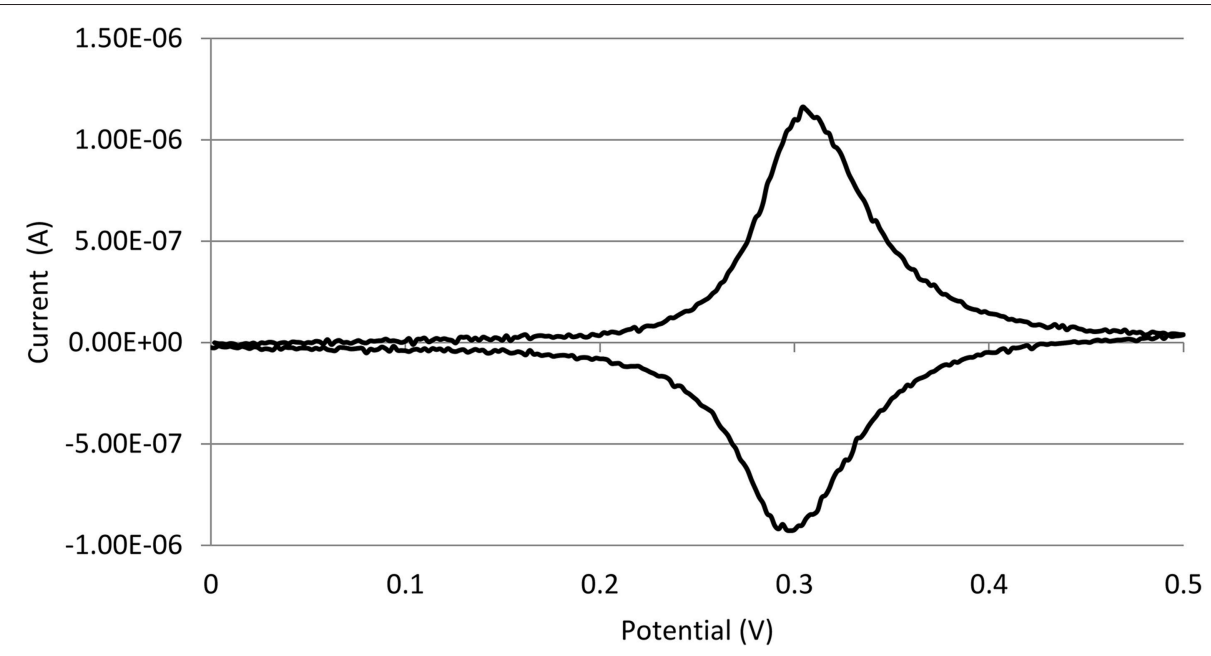

FIGURE 3 | Characterization of Os-HRP modified carbon electrode. Characterization of the Os-HRP modified carbon electrode: cyclic voltammetry was performed for the basic characterization of the modified electrode. Cyclic voltammetry was conducted at a scan rate of $20 \mathrm{mV} / \mathrm{s}$ from 0.0 to $+0.5 \mathrm{~V}$ at room temperature.

a linear increase was observed similar to control (Figure 4A). Upon addition of exogenous SOD to PSII membranes during illumination, a fast increase in reduction current was observed bringing a considerable change of about $600 \mathrm{pA}$. The fast increase was followed by a rapid drop however; the reduction current was still higher as compared to reduction current recorded before the addition of SOD. The addition of CAT completely suppressed the reduction current by about 100\% (Figure 4B). These results show that under illumination of PSII membranes with a continuous white light, $\mathrm{H}_{2} \mathrm{O}_{2}$ production in PSII membrane is contributed via dismutation of $\mathrm{O}_{2}^{\bullet-}$.

\section{DISCUSSION}

In the current study, we used spectroscopic and amperometric techniques to measure the production of ROS in spinach PSII membrane. Our prime objective was to study the effect of high light stress in PSII membrane reflected by ROS production primarily the generation of $\mathrm{H}_{2} \mathrm{O}_{2}$ as the stress response formed via the dismutation of $\mathrm{O}_{2}^{\bullet-}$. Superoxide anion radical which is known to be formed by one-electron reduction of molecular oxygen was measured under light illumination (Figure 1). EPR spin-trapping data obtained using the urea-type herbicide (DCMU) supports the evidence on the involvement of loosely bound plastosemiquinone in $\mathrm{O}_{2}^{\bullet-}$ production (Figure 2B). Suppression of EMPO-OOH adduct EPR signal is in agreement with our previously published results where contribution of loosely bound plastosemiquinone at or after the $\mathrm{Q}_{B}$ site (DCMUsensitive site) might contribute to the overall $\mathrm{O}_{2}^{--}$production (Yadav et al., 2014). The EMPO-OOH adduct EPR signal in the presence of DCMU indicates that molecular oxygen is reduced prior to the $\mathrm{Q}_{B}$ site which is known to occur due to reduction of molecular oxygen by $\mathrm{Pheo}^{\bullet-}$ or $\mathrm{Q}_{A}^{\bullet-}$ which serves as electron donors to molecular oxygen due to their low redox potentials
(Pospísiil, 2012). The observation that the EMPO-OOH adduct was completely suppressed in PSII membranes illuminated in presence of SOD indicates that $\mathrm{O}_{2}^{\bullet-}$ formed during the light illumination dismutates to $\mathrm{H}_{2} \mathrm{O}_{2}$ prior to its interaction with spin trap (Figure 2A). It can be concluded here that the $\mathrm{H}_{2} \mathrm{O}_{2}$ formed in PSII membrane under light illumination is contributed by the dismutation of $\mathrm{O}_{2}^{--}$.

Amperometric methods for the direct detection of $\mathrm{H}_{2} \mathrm{O}_{2}$ has been used since last decades in animal cells (Mouithys-Mickalad et al., 2001; Inoue et al., 2010) however, very limited evidences exist on its application in plant cells (Cleland and Grace, 1999). Amperometric measurements have been implemented at the level of protoplast to study the photosynthetic activity under the effect of benzoquinone (Yasukawa et al., 1998, 1999). Redox response of benzoquinone, $\mathrm{p}$-hydroquinone and oxygen was measured by placing a microelectrode close to an algal protoplast to localize concentration of these species (Yasukawa et al., 1999). Direct detection of $\mathrm{H}_{2} \mathrm{O}_{2}$ using electrochemical methods; however, had never been reported previously in photosynthetic organelles. $\mathrm{H}_{2} \mathrm{O}_{2}$ detection in subchloroplast oxygen-evolving PSII particles and isolated reaction center complexes of PSII has been studied using luminol-peroxidase chemiluminescence and pulse photoactivation (Zastrizhnaya et al., 1997). Production of $\mathrm{H}_{2} \mathrm{O}_{2}$ was detected in PSII membranes using AR fluorescent assay (Yadav and Pospísil, 2012). Levels of $\mathrm{H}_{2} \mathrm{O}_{2}$ including $\mathrm{O}_{2}^{--}$and singlet oxygen has been determined by using both histochemical and fluorescent probes in leaves and thylakoids (Zulfugarov et al., 2014), however, there exist arguments over the selectivity of the molecular probes used.

Two different approaches of the detection of $\mathrm{H}_{2} \mathrm{O}_{2}$ via electrochemical methods are being used in animal cells. The detection of $\mathrm{H}_{2} \mathrm{O}_{2}$ is either via a non-mediator or a mediator based biosensor device (Lin et al., 2000; Nakabayashi and 

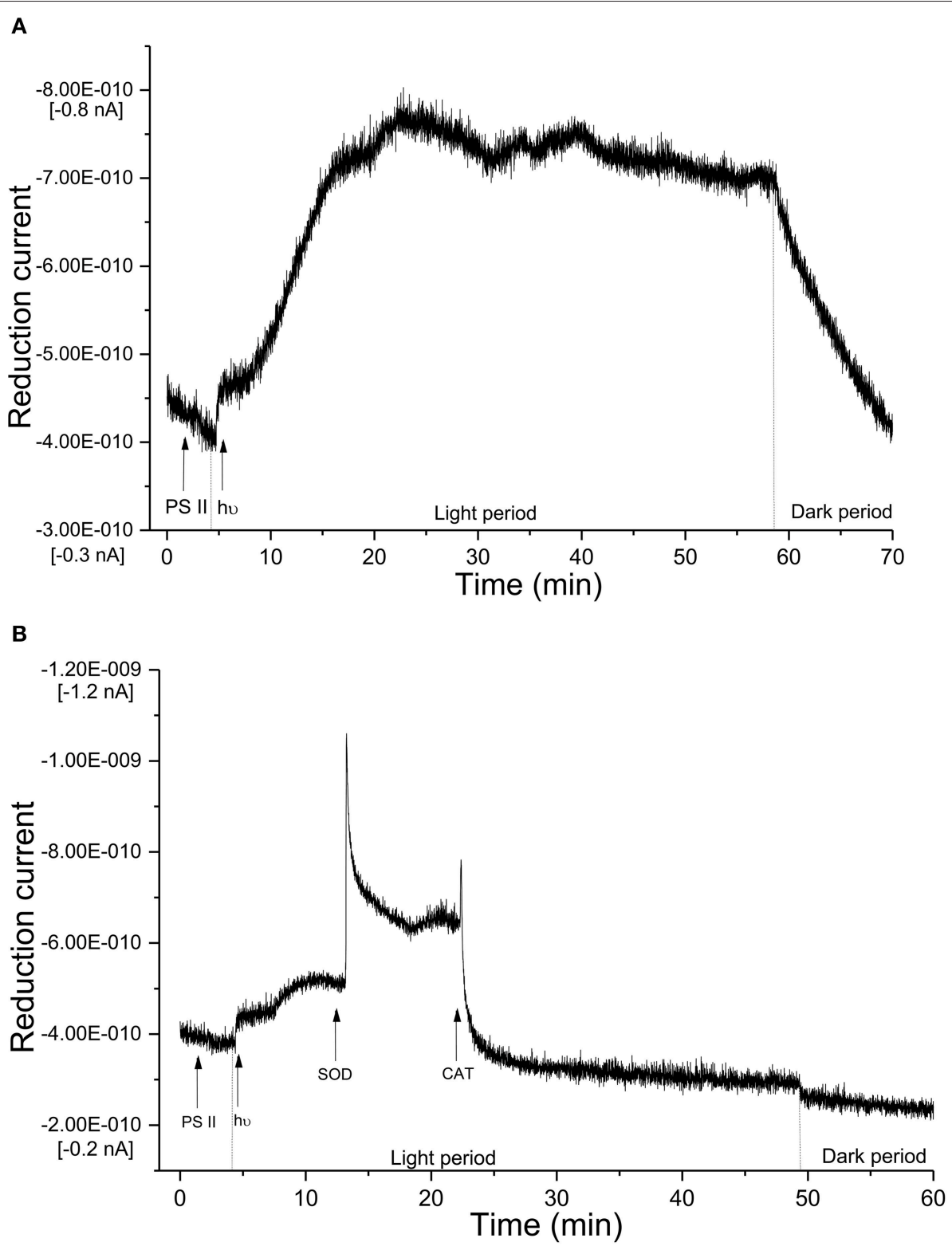

FIGURE 4 | Real-time monitoring of reduction current for hydrogen peroxide in PSII membrane. (A) Kinetics of the production of $\mathrm{H}_{2} \mathrm{O}_{2}$ was measured using Os-HRP modified carbon electrode during light illumination in PSIl membranes. The light illumination was started at 5 min from the start of the measurement and the reduction current was measured for a duration of $1 \mathrm{~h}$. (B) Effect of SOD and CAT on reduction current was measured in the presence of SOD (400 U/ml) and SOD + CAT $(400 \mathrm{U} / \mathrm{ml}$ each).

Yoshikawa, 2000; Yao et al., 2005; Wang and Zhang, 2006; Camacho et al., 2007; Jia, 2008; Radi et al., 2009; Ahammad, 2013). In non-mediator based biosensor, the transfer of electron occurs between the electrode and the enzyme (Ahammad, 2013). The preparation process being very simple, the non-mediator based biosensors have been extensively used in the past. In the mediator based biosensor device, the mediator plays a key role to shuttle electron between the electrode and the enzyme (Scheme 1). Most commonly, methylene blue, ferrocene and carboxylic acid are used as mediators (Lin et al., 2000; Tian et al.,
2001; Li et al., 2004; Tripathi et al., 2006; Senel et al., 2010). The mediator in the case of HRP is pointed to be important because the shuttling of electron between electrode and HRP is large as the active site of HRP is located deep in the protein sheath (Ahammad, 2013). In our current device, Os acts as a mediator where $\mathrm{Os}^{2+}$ is reduced to $\mathrm{Os}^{3+}$ in the process (Scheme 1). Different modified electrode has been introduced in the past, the detection limit in most case were in the range of $\mu \mathrm{M}$ concentration with a limited contribution where mediator-based HRP biosensor reached a lower detection limit in the range of 
tens-hundreds nm concentration (Chen et al., 2006; Zhang et al., 2008; Lu et al., 2010).

Using Os-HRP modified carbon electrode, we have observed a change in the reduction current during illumination of PSII membranes reflecting the production of $\mathrm{H}_{2} \mathrm{O}_{2}$ (Figure 4A). A change of $\sim 400 \mathrm{pA}$ reflects generation of $\mathrm{H}_{2} \mathrm{O}_{2}$ which was then found to be stable in the period of 20-60 min of light illumination. The reduction current was found to drop immediately under dark condition. Based on the considerable changes monitored in reduction current, the biosensor device is claimed to be sensitive for its application in photosynthetic samples.

ROS generated in the cell or organelles are eliminated by antioxidant enzymes such as SOD, glutathione peroxidase, CAT or by low molecular antioxidants such as vitamins, glutathione etc. (Halliwell and Gutteridge, 2007). When SOD which dismutates $\mathrm{O}_{2}^{\bullet-}$ to $\mathrm{H}_{2} \mathrm{O}_{2}$ was added to the illuminated PSII membrane, the reduction current for $\mathrm{H}_{2} \mathrm{O}_{2}$ was observed to gradually enhance leading to the conclusion that the $\mathrm{H}_{2} \mathrm{O}_{2}$ generated in the PSII membrane is formed via the formation of $\mathrm{O}_{2}^{\bullet-}$. The addition of SOD (Figure 4B) during the light illumination drastically enhanced the reduction current by 600 pA followed by a sudden drop indicate the fast conversion of $\mathrm{O}_{2}^{\bullet-}$ into $\mathrm{H}_{2} \mathrm{O}_{2}$ available in the PSII pool. This is in agreement with observed result with EPR signal of the EMPO-OOH adduct observed under the effect of SOD (Figure 2A). The subsequent addition of CAT which converts $\mathrm{H}_{2} \mathrm{O}_{2}$ to $\mathrm{H}_{2} \mathrm{O}$ and molecular oxygen brings back the reduction current close to the value observed under dark condition.

Electrochemical detection of $\mathrm{H}_{2} \mathrm{O}_{2}$ is suggested here to be of great importance in addition to other methods that has been used in the recent past. In the detailed study performed by Šnyrychová and co-workers, different $\mathrm{H}_{2} \mathrm{O}_{2}$ detecting probes were tested. Probes such as amplex red and amplex ultra-red were found to be sensitive to light and thus are not appropriate for the study on the generation of $\mathrm{H}_{2} \mathrm{O}_{2}$ in plant sample where effect of light stress is frequently studied. Based on the results, the authors also suggested that these probes should be used with caution to avoid artifacts (Šnyrychová et al., 2009). In addition to this, the toxicity caused by the exogenous addition of probes cannot be completely excluded. The method of electrochemical measurements is also preferred because of the simplicity, lowcost, high-sensitivity and selectivity (Ahammad, 2013). The simplicity and low-cost of electrochemical measurements is because of the fact that the electrodes can be used for endless time with easy fabrication with designated mediator and enzyme and overnight incubation at $4{ }^{\circ} \mathrm{C}$ under dark condition or as per standards. Based on the redox potential of the redox couple, the modified electrode are specific for different species. Os-HRP modified electrode is specific for $\mathrm{H}_{2} \mathrm{O}_{2}$ and thus can be widely used in photosynthetic research where detection of $\mathrm{H}_{2} \mathrm{O}_{2}$ has always been a challenge. The sensitivity of the modified electrode depends on the size and the material used. In our current report, Os-HRP modified carbon electrode has been claimed to be sensitive and highly selective among other $\mathrm{H}_{2} \mathrm{O}_{2}$ detection techniques available till date. This fact opens the possibility for using Os-HRP modified electrode for $\mathrm{H}_{2} \mathrm{O}_{2}$ detection in photosystem I (PSI) where $\mathrm{H}_{2} \mathrm{O}_{2}$ is formed by the transfer of electron from reduced ferredoxin to molecular oxygen via ferredoxin-thioredoxin reductase (Gechev et al., 2006). Plasma membrane NADPH oxidase complex are considered as the major producer of ROS including $\mathrm{O}_{2}^{\bullet-}$ and $\mathrm{H}_{2} \mathrm{O}_{2}$ in cells (Sagi and Fluhr, 2001, 2006; Halliwell and Gutteridge, 2007). In addition to this, among the enzymatic source of $\mathrm{O}_{2}^{\bullet-}$ and $\mathrm{H}_{2} \mathrm{O}_{2}$, cell wall bound peroxidases, aminooxidases, flavin containing oxidases, oxalate, and plasma membrane oxidases are known to be involved (Bolwell et al., 2002; Mori and Schroeder, 2004; Svedruzic et al., 2005). In the case of apoplastic oxidative burst, ROS are produced by cell wall bound oxidases, peroxidases and polyamine oxidases (Minibayeva et al., 1998, 2009). Thus, the current electrode also opens the possibility for measuring generation of $\mathrm{H}_{2} \mathrm{O}_{2}$ from different and localized structures of plants and animals cells.

\section{AUTHOR CONTRIBUTIONS}

$\mathrm{AP}$ and SK contributed to the conception and design of the work. AP, AK, MS, HK, TS performed the measurements. AP analyzed, interpreted the data and drafted the manuscript. AK, PP participated in drafting the manuscript. SK, MK, and MT revised it critically for important content. All authors approved the final version of the manuscript.

\section{ACKNOWLEDGMENTS}

This work was funded by the MEXT-Supported Program for the Strategic Research Foundation at Private Universities, Japan. PP would like to thank Ministry of Education, Youth and Sports of the Czech Republic grants no. LO1204 (National Program of Sustainability I), no.CZ.1.07/2.3.00/30.0041 (Support for Building Excellent Research Teams and Intersectoral Mobility at Palacký University) and by Czech Science Foundation grant no. GP13-29294S. We thank Ketaki Vasant Phadke (Department of Biophysics, Palacký University) for cross-checking the manuscript for errors.

\section{SUPPLEMENTARY MATERIAL}

The Supplementary Material for this article can be found online at: http://journal.frontiersin.org/article/10.3389/fpls.2015. 00862 


\section{REFERENCES}

Ahammad, A. J. S. (2013). Hydrogen peroxide biosensors based on horseradish peroxidase and hemoglobin. J. Biosens. Bioelectron. S9:001. doi: 10.4172/21556210.S9-001

Ananyev, G., Renger, G., Wacker, U., and Klimov, V. (1994). The photoproduction of superoxide radicals and the superoxide-dismutase activity of photosystem II. The possible involvement of cytochrome b559. Photosynth. Res. 41, 327-338. doi: $10.1007 / \mathrm{BF} 00019410$

Arató, A., Bondarava, N., and Krieger-Liszkay, A. (2004). Production of reactive oxygen species in chloride- and calcium-depleted photosystem II and their involvement in photoinhibition. Biochim. Biophys. Acta 1608, 171-180. doi: 10.1016/j.bbabio.2003.12.003

Berthold, D. A., Babcock, G. T., and Yocum, C. F. (1981). A highly resolved oxygen evolving photosystem II preparation from spinach thylakoid membranes. FEBS Lett. 134, 231-234. doi: 10.1016/0014-5793(81)80608-4

Bolwell, G. P., Bindschedler, L. V., Blee, K. A., Butt, V. S., Davies, D. R., Gardner, S. L., et al. (2002). The apoplastic oxidative burst in response to biotic stress in plants: a three-component system. J Exp. Bot. 53, 1367-1376. doi: 10.1093/jexbot/53.372.1367

Camacho, C., Matías, J. C., Chico, B., Cao, R., Gómez, L., Simpson, B. K., et al. (2007). Amperometric biosensor for hydrogen peroxide, using supramolecularly immobilized horseradish peroxidase on the $\beta$ cyclodextrin-coated gold electrode. Electroanalysis 19, 2538-2542. doi: 10.1002/elan.200703993

Chen, S., Yin, C., Strasser, R. J., Govindjee, Yang, C., and Qiang, S. (2012). Reactive oxygen species from chloroplasts contribute to 3-acetyl-5- isopropyltetramic acid-induced leaf necrosis of Arabidopsis thaliana. Plant Physiol. Biochem. 52, 38-51. doi: 10.1016/j.plaphy.2011.11.004

Chen, S., Yuan, R., Chai, Y., Xu, L., Wang, N., Li, X. et al. (2006). Amperometric hydrogen peroxide biosensor based on the immobilization of Horseradish Peroxidase (HRP) on the layer-by-layer assembly films of gold colloidal nanoparticles and toluidine blue. Electroanalysis 18, 471-477. doi: 10.1002/elan.200503424

Chen, W., Li, B., Xu, C., and Wang, L. (2009). Chemiluminescence flow biosensor for hydrogen peroxide using DNAzyme immobilized on eggshell membrane as a thermally stable biocatalyst. Biosens. Bioelectron. 24, 2534-2540. doi: 10.1016/j.bios.2009.01.010

Cleland, R. E., and Grace, S. C. (1999). Voltammetric detection of superoxide production by photosystem II. FEBS Lett. 457, 348-352. doi: 10.1016/S00145793(99)01067-4

Ferreira, K. N., Iverson, T. M., Maghlaoui, K., Barber, J., and Iwata, S. (2004). Architecture of the photosynthetic oxygen-evolving center. Science 303, 1831-1838. doi: 10.1126/science.1093087

Ford, R. C., and Evans, M. C. W. (1983). Isolation of a photosystem II from higher plants with highly enriched oxygen evolution activity. FEBS Lett. 160, 159-164. doi: 10.1016/0014-5793(83)80957-0

Foyer, C. H., and Shigeoka, S. (2011). Understanding oxidative stress and antioxidant functions to enhance photosynthesis. Plant Physiol. 155, 93-100. doi: $10.1104 /$ pp.110.166181

Gechev, T. S., Van Breusegem, F., Stone, J. M., Denev, I., and Laloi, C (2006). Reactive oxygen species as signals that modulate plant stress responses and programmed cell death. Bioessays 28, 1091-1101. doi: 10.1002/bies.20493

Guskov, A., Kern, J., Gabdulkhakov, A., Broser, M., Zouni, A., and Saenger, W. (2009). Cynobacterial photosystem II at $2.9 \AA$ resolution and the role of quinones, lipids, channels and chloride. Nat. Struct. Mol. Biol. 16, 334-342. doi: 10.1038/nsmb.1559

Halliwell, B., and Gutteridge, J. M. C. (2007). Free Radicals in Biology and Medicine, 4th Edn. New York, NY: Oxford University Press.

Inoue, K. Y., Ino, K., Shiku, H., Kasai, S., Yasukawa, T., Mizutani, F., et al. (2010). Electrochemical monitoring of hydrogen peroxide released from leucocytes on horseradish peroxidase redox polymer coated electrode chip. Biosens. Bioelectron. 25, 1723-1728. doi: 10.1016/j.bios.2009.12.014

Jia, J. (2008). Hydrogen peroxide biosensor based on horseradish peroxidase- Au nanoparticles at a viologen grafted glassy carbon electrode. Microchim. Acta 163, 237-241. doi: 10.1007/s00604-008-0002-9

Kafi, A. K., Wu, G., and Chen, A. (2009). A novel hydrogen peroxide biosensor based on the immobilization of horseradish peroxidase onto Au-modified titanium dioxide nanotube arrays. Biosens. Bioelectron. 24, 566-571. doi: 10.1016/j.bios.2008.06.004

Kawakami, K., Umena, Y., Kamiya, N., and Shen, J.-R. (2011). Structure of the catalytic, inorganic core of oxygen-evolving photosystem II at $1.9 \AA$ resolution. J. Photochem. Photobiol. B 104, 9-18. doi: 10.1016/j.jphotobiol.2011. 03.017

Krieger-Liszkay, A. (2005). Singlet oxygen production in photosynthesis. J. Exp. Bot. 56, 337-346. doi: 10.1093/jxb/erh237

Lei, C. X., Long, L. P., and Cao, Z. L. (2005). An $\mathrm{H}_{2} \mathrm{O}_{2}$ biosensor based on immobilization of horseradish peroxidase labeled nano-Au in silica sol-gel/alginate composite film. Anal. Lett. 38, 1721-1734. doi: 10.1080/00032710500207762

Lei, C. X., Wang, H., Shen, G. L., and Yu, R. Q. (2004). Immobilization of enzymes on the nano-au film modified glassy carbon electrode for the determination of hydrogen peroxide and glucose. Electroanalysis 16, 736-740. doi: 10.1002/elan.200302877

Li, C. X., Deng, K. Q., Shen, G. L., and Yu, R. Q. (2004). Amperometric hydrogen peroxide biosensor based on horseradish peroxidase-labeled nano-Au colloids immobilized on poly(2,6-pyridinedicarboxylic acid) layer by cysteamine. Anal. Sci. 20, 1277-1281. doi: 10.2116/analsci.20.1277

Li, Z. H., Guedri, H., Viguier, B., Sun, S. G., and Marty, J. L. (2013). Optimization of hydrogen peroxide detection for a methyl mercaptan biosensor. Sensors 13, 5028-5039. doi: 10.3390/s130405028

Lichtenthaler, H. K. (1987). Chlorophylls and carotenoids: pigments of photosynthetic biomembranes. Methods Enzymol. 148, 350-382. doi: 10.1016/0076-6879(87)48036-1

Lin, X. Q., Chen, J., and Chen, Z. H. (2000). Amperometric biosensor for hydrogen peroxide based on immobilization of horseradish peroxidase on methylene blue modified graphite electrode. Electroanalysis 12, 306-310. doi: 10.1002/(sici)1521-4109(20000301)

Liu, X., Luo, L., Ding, Y., Xu, Y., and Li, F. (2011). Hydrogen peroxide biosensor based on the immobilization of horseradish peroxidase on $\gamma-\mathrm{Al}_{2} \mathrm{O}_{3}$ nanoparticles/chitosan film-modified electrode. J. Solid State Electrochem. 15, 447-453. doi: 10.1007/s10008-010-1120-y

Loew, N., Wollenberger, U., Scheller, F. W., and Katterle, M. (2009). Direct electrochemistry and spectroelectrochemistry of osmium substituted horseradish peroxidase. Bioelectrochemistry 76, 28-33. doi: 10.1016/j.bioelechem.2009.03.015

Loll, B., Kern, J., Saenger, W., Zouni, A., and Biesiadka, J. (2005). Towards complete cofactor arrangement in the $3.0 \AA$ A resolution structure of photosystem II. Nature 438, 1040-1044. doi: 10.1038/nature04224

Lu, L., Zhang, L., Zhang, X., Wu, Z., Huan, S., Shen, G. et al. (2010). A $\mathrm{MgO}$ nanoparticles composite matrix-based electrochemical biosensor for hydrogen peroxide with high sensitivity. Electroanalysis 22, 471-477. doi: 10.1002/elan.200900429

Luo, L., Zhu, L., Xu, Y., Shen, L., Wang, X., Ding, Y. et al. (2011). Hydrogen peroxide biosensor based on horseradish peroxidase immobilized on chitosan-wrapped $\mathrm{NiFe}_{2} \mathrm{O}_{4}$ nanoparticles. Microchim. Acta 174, 55-61. doi: 10.1007/s00604-011-0591-6

Mills, A., Tommons, C., Bailey, R. T., Tedford, M. C., and Crilly, P. J. (2007). Reversible, fluorescence-based optical sensor for hydrogen peroxide. Analyst 132, 566-571. doi: 10.1039/b618506a

Minibayeva, F., Kolesnikov, O., Chasov, A., Beckett, R. P., Lüthje, S., Vylegzhanina, N., et al. (2009). Wound-induced apoplastic peroxidase activities: their roles in the production and detoxification of reactive oxygen species. Plant Cell. Environ. 32, 497-508. doi: 10.1111/j.1365-3040.2009.01944.x

Minibayeva, F., Kolesnikov, O. P., and Gordon, L. K. (1998). Contribution of a plasma membrane redox system to the superoxide production by wheat root cells Protoplasma 205, 101-106. doi: 10.1007/BF01279299

Mori, I. C., and Schroeder, J. I. (2004). Reactive oxygen species activation of plant $\mathrm{Ca} 2+$ channels. A signaling mechanism in polar growth, hormone transduction, stress signaling, and hypothetically mechanotransduction. Plant Physiol. 135, 702-708. doi: 10.1104/pp.104.042069

Mouithys-Mickalad, A., Deby-Dupont, G., Nys, M., Lamy, M., and Deby, C. (2001). Oxidative processes in human promonocytic cells (THP1) after differentiation into macrophages by incubation with Chlamydia pneumoniae extracts. Biochem. Biophys. Res. Commun. 287, 781-788. doi: $10.1006 /$ bbrc. 2001.5643 
Mubarakshina, M. M., and Ivanov, B. N. (2010). The production and scavenging of reactive oxygen species in the plastoquinone pool of chloroplast thylakoid membranes. Physiol. Plant. 140, 103-110. doi: 10.1111/j.13993054.2010.01391.x

Nakabayashi, Y., and Yoshikawa, H. (2000). Amperometric biosensors for sensing of hydrogen peroxide based on electron transfer between horseradish peroxidase and ferrocene as a mediator. Anal. Sci. 16, 609-613. doi: 10.2116/analsci.16.609

Pospíšil, P. (2009). Production of reactive oxygen species by photosystem II. Biochim. Biophys. Acta 1787, 1151-1160. doi: 10.1016/j.bbabio.2009.05.005

Pospísil, P. (2011). Enzymatic function of cytochrome b559 in photosystem II. J Photochem. Photobiol. B 104, 341-347. doi: 10.1016/j.jphotobiol.2011.02.013

Pospíšil, P. (2012). Molecular mechanisms of production and scavenging of reactive oxygen species by photosystem II. Biochim. Biophys. Acta 1817, 218-231. doi: 10.1016/j.bbabio.2011.05.017

Pospíšil, P., Arató, A., Krieger-Liszkay, A., and Rutherford, A. W. (2004). Hydroxyl radical generation by Photosystem II. Biochemistry 43, 6783-6792. doi: $10.1021 /$ bi036219i

Pospíšil, P., Šnyrychová, I., Kruk, J., Strzałka, K., and Nauš, J. (2006). Evidence that cytochrome b559 is involved in superoxide production in Photosystem II: effect of synthetic short-chain plastoquinones in a cytochrome b559 tobacco mutant. Biochem. J. 397, 321-327. doi: 10.1042/BJ20060068

Prasad, A., and Pospíśil, P. (2012). Ultra-weak photon emission induced by visible light and ultraviolet A radiation via photoactivated skin chromophores: in-vivo charge coupled device imaging. J. Biomed. Opt. 17:085004. doi: 10.1117/1.JBO.17.8.085004

Radi, A. E., Muñoz-Berbel, X., Cortina-Puig, M., and Marty, J. L. (2009). A third generation hydrogen peroxide biosensor based on horseradish peroxidase covalently immobilized on electrografted organic film on screen-printed carbon electrode. Electroanalysis 21, 1624-1629. doi: 10.1002/elan.200904587

Rappaport, F., and Diner, B. A. (2008). Primary photochemistry and energetics leading to the oxidation of the (Mn)4Ca cluster and to the evolution of molecular oxygen in Photosystem II. Coord. Chem. Rev. 252, 259-272. doi: 10.1016/j.ccr.2007.07.016

Sagi, M., and Fluhr, R. (2001). Superoxide production by plant homologues of the Gp91phox NADPH oxidase. modulation of activity by calcium and by tobacco mosaic virus infection. Plant Physiol. 126, 1281-1290. doi: 10.1104/pp.126.3.1281

Sagi, M., and Fluhr, R. (2006). Production of reactive oxygen species by plant NADPH oxidases. Plant Physiol. 141, 336-340. doi: 10.1104/pp.106.078089

Sanford, A. L., Morton, S. W., Whitehouse, K. L., Oara, H. M., Lugo-Morales, L. Z., Roberts, J. G., et al. (2011). Voltammetric detection of hydrogen peroxide at carbon fiber microelectrodes. Anal Chem. 82, 5205-5210. doi: 10.1021/ac100536s

Schmitt, F. J., Renger, G., Friedrich, T., Kreslavksi, V. D., Zharmukhadmedov, S. K., Los, D. A., et al. (2014). Reactive oxygen species: re-evaluation of generation, monitoring and role in stress-signaling in phototrophic organisms. Biochim. Biophys. Acta 1837, 385-848. doi: 10.1016/j.bbabio.2014.02.005

Schröder, W. P., and Åkerlund, H.-E. (1990). "Hydrogen peroxide production in photosystem II preparations," in Current Research in Photosynthesis, Vol. 1, ed M. Baltscheffsky (Dordrecht: Kluwer Academic Publisher), 901-904.

Senel, M. C., Cevik, E., and Abasiyanı, M. F. (2010). Amperometric hydrogen peroxide biosensor based on covalent immobilization of horseradish peroxidase on ferrocene containing polymeric mediator. Sens. Actuators. B Chem. 145, 444-450. doi: 10.1016/j.snb.2009.12.055

Shao, N., Krieger-Liszkay, A., Schroda, M., and Beck Christoph, F. (2007). A reporter system for the individual detection of hydrogen peroxide and singlet oxygen: its use for the assay of reactive oxygen species produced in vivo. Plant J. 50, 475-487. doi: 10.1111/j.1365-313X.2007.03065.x

Šnyrychová, I., Ayaydin, F., and Hideg, É. (2009). Detecting hydrogen peroxide in leaves in vivo-a comparison of methods. Physiol. Plant. 135, 1-18. doi: 10.1111/j.1399-3054.2008.01176.x

Svedruzic, D., Jónsson, S., Toyota, C. G., Reinhardt, L. A., Ricagno, S, Lindqvist, Y., et al. (2005). The enzymes of oxalate metabolism: unexpected structures and mechanisms. Arch. Biochem. Biophys. 433, 176-192. doi: 10.1016/j.abb.2004.08.032

Tian, F., Xu, B., Zhu, L., and Zhu, G. (2001). Hydrogen peroxide biosensor with enzyme entrapped within electrodeposited polypyrrole based on mediated sol-gel derived composite carbon electrode. Anal. Chim. Acta 443, 9-16. doi: 10.1016/S0003-2670(01)01187-4

Tiwari, A., and Pospísil, P. (2009). Superoxide oxidase and reductase activity of cytochrome b559 in photosystem II. Biochim. Biophys. Acta 1787, 985-994. doi: 10.1016/j.bbabio.2009.03.017

Tiwari, I., and Singh, M. (2011). Preparation and characterization of methylene blue-SDS-multiwalled carbon nanotubes nanocomposite for the detection of hydrogen peroxide. Microchim. Acta 174, 223-230. doi: 10.1007/s00604-0110620-5

Tripathi, V. S., Kandimalla, V. B., and Ju, H. (2006). Amperometric biosensor for hydrogen peroxide based on ferrocene-bovine serum albumin and multiwall carbon nanotube modified ormosil composite. Biosens. Bioelectron. 21, 1529-1535. doi: 10.1016/j.bios.2005. 07.006

Wang, G. H., and Zhang, L. M. (2006). Using novel polysaccharide-silica hybrid material to construct an amperometric biosensor for hydrogen peroxide. J. Phys. Chem. B 110, 24864-24868. doi: 10.1021/jp0657078

Wang, H. S., Pan, Q. X., and Wang, G. X. (2005). A biosensor based on immobilization of horseradish peroxidase in chitosan matrix cross-linked with glyoxal for amperometric determination of hydrogen peroxide. Sensors 5, 266-276. doi: 10.3390/s5040266

Yadav, D. K., and Pospíšil, P. (2012). Role of chloride ion in hydroxyl radical production in photosystem II under heat stress: electron paramagnetic resonance spin-trapping study. J. Bioenerg. Biomembr. 44, 365-372. doi: 10.1007/s10863-012-9433-4

Yadav, D. K., Prasad, A., Kruk, J., and Pospíšil, P. (2014). Evidence for the involvement of loosely bound plastosemiquinones in superoxide anion radical production in photosystem II. PLoS ONE 9:e115466. doi: 10.1371/journal.pone.0115466

Yang, Z., Zong, X., Ye, Z., Zhao, B., Wang, Q., and Wang, P. (2010). The application of complex multiple forklike $\mathrm{ZnO}$ nanostructures to rapid and ultrahigh sensitive hydrogen peroxide biosensors. Biomaterials 31, 7534-7541. doi: 10.1016/j.biomaterials.2010.06.019

Yao, H., Li, N., Wei, Y. L., and Zhu, J. J. (2005). A $\mathrm{H}_{2} \mathrm{O}_{2}$ biosensor based on immobilization of horseradishperoxidase in a gelatine network matrix. Sensors 5, 277-283. doi: 10.3390/s5040277

Yasukawa, T., Uchida, I., and Matsue, T. (1998). Permeation of redox species through a cell membrane of a single, living algal protoplast studied by microamperometry. Biochim. Biophys. Acta 1369, 152-158. doi: 10.1016/S00052736(97)00220-4

Yasukawa, T., Uchida, I., and Matsue, T. (1999). Microamperometric measurements of photosynthetic activity in a single algal protoplast. Biophys. J. 76, 1129-1135. doi: 10.1016/S0006-3495(99)77277-2

Zastrizhnaya, O. M., Khorobrykh, A. A., Khristin, M. S., and Klimov, V. V. (1997). Photoinduced production of hydrogen peroxide at the acceptor side of photosystem II. Biochemistry 62, 357-361.

Zhang, H. L., Lai, G. S., Han, D. Y., and Yu, A. M. (2008). An amperometric hydrogen peroxide biosensor based on immobilization of horseradish peroxidase on an electrode modified with magnetic dextran microspheres. Anal. Bioanal. Chem. 390, 971-977. doi: 10.1007/s00216-007-1748-3

Zhang, S., Weng, J., Pan, J., Tu, T., Yao, S., and Xu, C. (2003). Study on the photogeneration of superoxide radicals in Photosystem II with EPR spin trapping techniques. Photosynth. Res. 75, 41-48. doi: 10.1023/A:1022439009587

Zulfugarov, I. S., Tovuu, A., Eu, Y. J., Dogsom, B., Poudyal, R. S., Nath, K., et al. (2014). Production of superoxide from Photosystem II in a rice (Oryza sativa L.) mutant lacking PsbS. BMC Plant Biol. 14:242. doi: 10.1186/s12870-014-0242-2

Conflict of Interest Statement: The authors declare that the research was conducted in the absence of any commercial or financial relationships that could be construed as a potential conflict of interest.

Copyright (C) 2015 Prasad, Kumar, Suzuki, Kikuchi, Sugai, Kobayashi, Pospišil, Tada and Kasai. This is an open-access article distributed under the terms of the Creative Commons Attribution License (CC BY). The use, distribution or reproduction in other forums is permitted, provided the original author(s) or licensor are credited and that the original publication in this journal is cited, in accordance with accepted academic practice. No use, distribution or reproduction is permitted which does not comply with these terms. 